\title{
ОПРЕДЕЛЕНИЕ ИНДИВИДУАЛЬНОГО СОСТАВА СРЕДНИХ ФРАҚЦИИ СЛАНЦЕВОЙ СМОЛЫ ГАЗОХРОМАТОГРАФИЧЕСКИМ И СПЕКТРАЛЬНО-АНАЛИТИЧЕСКИМ МЕТОДАМИ
}

\author{
о. ЭйЗН, \\ кандидат технических наук
}

Э. АРУМЕЕЛ, Ю. ЭИЗЕН, Х. РАУДЕ, И. ПЫДЕР,

О. КИРРЕТ,

член-корреспондент АН ЭССР

Л. ЛАХЕ, М. ВЯНИКВЕР

Методика определения индивидуального состава средних фракций сланцевой смолы, образующихся при термическом разложении горючего сланца, до настоящего времени окончательно не разработана. Это объясняется чрезвычайно большим числом присутствующих во фракциях углеводородов и их изомеров. Поэтому успех определения индивидуального состава зависит преимущественно от методики разделения компонентов исследуемой смеси.

Для разделения углеводородов по типу и величине молекул часто используют хроматографирование на адсорбентах и точную ректификашию. Такой метод применим для разделения индивидуальных углеводородов во фракциях с пределами кипения до $120^{\circ}$.

В более высокой части, даже при точной ректификации в узких фракциях, остается настолько много компонентов, что подтверждение их наличия спектрально-аналитическим путем не является достаточно надежным.

В связи с этим определение индивидуального состава средних и высших фракций нуждается в новых методах разделения и выделения. С этой целью в последнее время нашли применение следующие методы: хроматография на бумаге, разделение на молекулярных ситах и тонкослойная хроматография. Однако, самым перспективным, на наш взгляд, является газохроматографический метод разделения. Преимущество газохроматографического метода, перед другими методами, заключается, прежде всего, в его высокой избирательности.

Несмотря на быстрое развитие газохроматографии, еще мало опубликовано работ по применению полупрепаративного метода для идентификации углеводородов с большим молекулярным весом. С помощью полупрепаративного газохроматографическото метода можно получить необходимые для спектрального анализа количества исследуемого материала. Газохроматографически выделенные пики часто настолько чисты, что становится возможным определение индивидуального соединения с помощью спектрального анализа. 


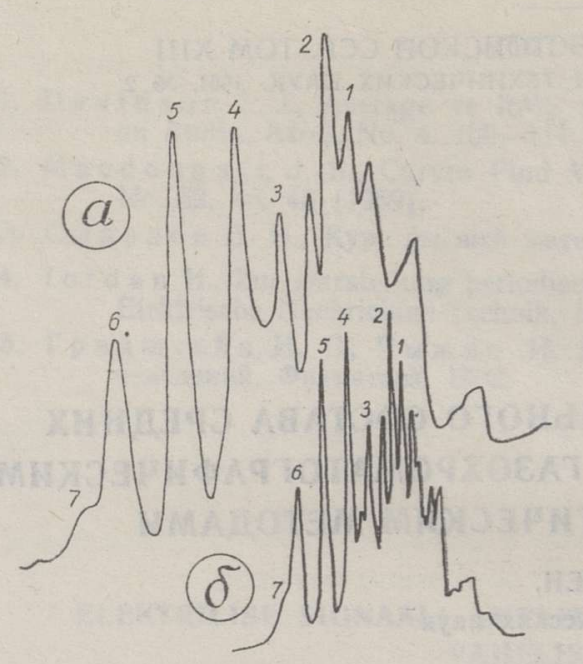

В целях выяснения характера биологического действия смолы камерных печей авторам настоящей работы пришлось определить индивидуальный состав присутствующих в смоле ароматических соединений

Для решения этой задачи была разработана соответствующая методика и определен химический состав ароматических углеводородов смолы камерной печи, кипящих до $300^{\circ}$

C целью идентификации арома тических углеводородов может быть с успехом применен ультрафиолетовый спектральный анализ. Количество исследуемого вещества в случае ультрафиолетового метода в 100

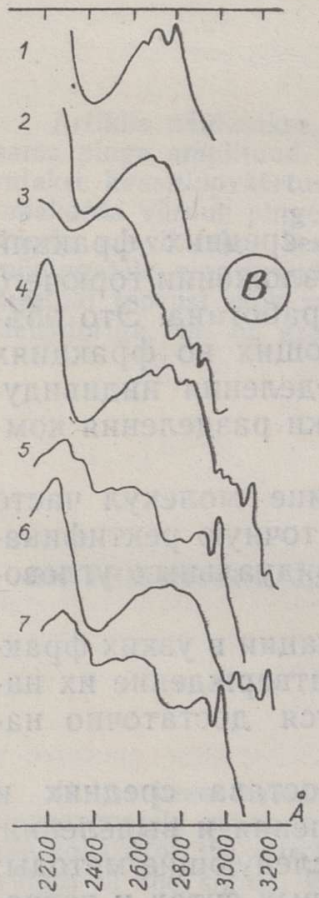

200 раз меньше того количества, которое необходимо для проведения анализа в макрокюветах спектрометра ИКС-14. Қоличество вещества, необходимое для проведения ультрафиолетового спектрального анализа, может быть получено на аналитических газохроматографических колонках.

В настоящей работе полупрепаративное выделение и отбор фракции проводились на газохроматографе УХ-1. Длина колонки составляла 6 м, диаметр - 8 мм, наполнителем колонки служил диатомитовый кирпич 40-70 меш, покрытый 20\%-ным

Рис. 1. Газохроматографнческий анализ ароматических углеводородов фракции $221-236^{\circ}$ смолы камерных печей. $a-$ по. лупрепаративная газовая хроматограмма. Количество веще щества $50 \mu \Omega$. Газовый хроматограф УХ-1. Рабочая температура $200^{\circ}$. Катарометр. Полигликоль 4000, 20\%; б - аналитическая газовая хроматограмма. Количество вещества $0,2 \mu л$. Газохроматограф «Шендон». Пламенно-ионизационный детектор. Рабочая температура $220^{\circ}$. Колонка № 3 (табл. 1); 8 результаты спектрального анализа соединений, выделенных на полупрепаративном газохроматографе: 1 - 2-метилтетралин, 2 - 1-метилтетралин, 3 - производная индена, 4 - нафталин, 5 - тионафтен, 6 - 2-метилнафталин, 7 - метилтионафтен.

полигликолем 4000, в качестве газа-носителя применялся водород. Количество вводимой пробы составляло 10-100 $\mu л$. Пик хроматограммы, пригодный для идентификации, образуется из $1-3 \mu л$ вещества. Фракции отбирались в стеклянные трубки, наполненные этанолом или гептаном. Трубки охлаждались твердой углекислотой.

При отборе твердых проб предварительно накаливали металлическую иглу приемника. Без этого игла либо засорялась кристаллами, либо следующая фракция загрязнялась кристаллами предыдущей.

Спектр соединений, растворенных в этаноле или гептане, снимался на двухлучевом ультрафиолетовом спектрофотометре, сконструированном в секторе физико-химических исследований Института химии АН ЭСCP. 
Полученные спектры позволили идентифицировать углеводороды, ныделенные газохроматографически. На рис. 1 и 2 приведены данные по идентификации двух фракций ароматических углеводородов смолы камерных печей.

Данные ультрафиолетового спектрального анализа по идентификации углеводородов уточнялись и дополнялись данными аналитической газохроматографин.

Число статей, посвященных газохроматографическому анализу нафталиновых углеводородов, весьма невелико $[1-4]$.

В данной работе газохроматографический анализ ароматических

Рис. 2. Газохроматографический анализ фракции 266-272 ароматических углеводородов камерных печей. $a$ - полупрепаративная газовая хроматограмма. Количество вешества $50 \mu л$. Газовый хроматограф УХ-1. Рабочая температура $200^{\circ}$. Қатарометр. Полигликоль $4000,20 \%$; $\sigma$ - аналитическая газовая хроматограмма. Количество вещества $0,2 \mu л$. Газохроматограф «ендон». Пламенно-ионизационный детектор. Рабочая температура $150^{\circ}$. Колонка № 2 (табл. 1); в - результаты спектрального анализа соединений, выделенных на препаративном газохроматографе. 1 - 1-пропилнафталин, 2 - 1,2диметилнафталин, 3 - метилдифенил, 4 - аценафтен.

углеводородов осуществлялся на хроматографе фирмы «Шендон» с пламенно-ионизационным детектором. Подробное описание применявшихся колоногі жидких фаз и условий опытов приведено в табл. 1
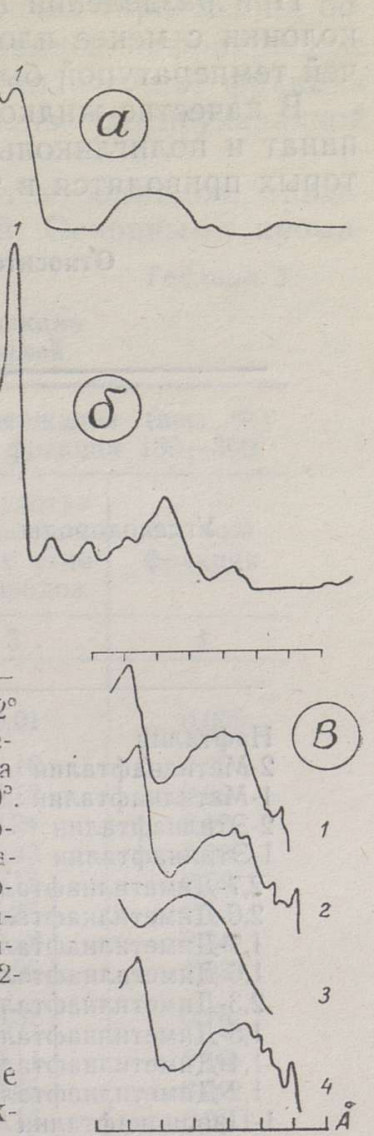

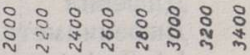

Таблица 1

Характеристика колонок, применявшихся при определении относительных времен удерживания углеводородов

\begin{tabular}{|c|c|c|c|c|}
\hline & \multicolumn{4}{|c|}{ Колонки } \\
\hline & 1 & 2 & 3 & 4 \\
\hline Жидкая фаза, \% & $\frac{\text { Аннезон Л, }}{25}$ & $\begin{array}{l}\text { Поли- } \\
\text { этилен- } \\
\text { гликоль } \\
4000,20\end{array}$ & $\begin{array}{c}\text { Поли- } \\
\text { этилен- } \\
\text { гликоль- } \\
\text { адипинат, } 25\end{array}$ & $\begin{array}{c}\text { Поли- } \\
\text { этилен- } \\
\text { гликоль- } \\
\text { фталат, } 25\end{array}$ \\
\hline Твердая, фаза, меш & $\begin{array}{l}\text { Силопел, } \\
60-72\end{array}$ & $\begin{array}{c}\text { Инзенский } \\
\text { Диатомито- } \\
\text { вый кирпич, } \\
30 \div 70\end{array}$ & $\begin{array}{c}\text { Силоцел, } \\
60-72\end{array}$ & $\begin{array}{c}\text { Силоцел, } \\
60-72\end{array}$ \\
\hline $\begin{array}{l}\text { Длина, м } \\
\text { Внутренний диа- } \\
\text { метр, мм }\end{array}$ & $\begin{array}{l}6 \\
4 \\
4\end{array}$ & $\begin{array}{c}2,72 \\
4\end{array}$ & $\begin{array}{l}6 \\
4\end{array}$ & $\begin{array}{l}6 \\
4\end{array}$ \\
\hline Гас-носитель & & смесь водорода & и аргона $1:$ & \\
\hline $\begin{array}{c}\text { Температура ко- } \\
\text { лонки, }{ }^{\circ} \mathrm{C}\end{array}$ & $\begin{array}{l}250 \\
280\end{array}$ & 150 & 220 & 200 \\
\hline $\begin{array}{l}\text { Анализируемая } \\
\text { группа углево- } \\
\text { дородов }\end{array}$ & $\begin{array}{l}\text { Аромати- } \\
\text { ческие } \\
\text { углеводо- } \\
\text { роды }\end{array}$ & Нафталины & $\begin{array}{l}\text { Ароматнче. } \\
\text { ские углев - } \\
\text { дороды }\end{array}$ & $\begin{array}{l}\text { Ароматиче- } \\
\text { ские углево- } \\
\text { дороды }\end{array}$ \\
\hline
\end{tabular}


При разделении нафталиновых углеводородов использовались 2,7 м колонки с менее плотным наполнителем. При этом оптимальной рабочей температурой была $150^{\circ} \mathrm{C}$.

В качестве жидкой фазы исследовались апиезон Л, полигликольадипинат и полигликольфталат, данные о разделительной способности которых приводятся в табл. 2.

Таблица 2

Относительные времена удерживания бициклических ароматических углеводородов

$1,3,5$-триэтилбензол $=100$

\begin{tabular}{|c|c|c|c|c|c|}
\hline \multirow{4}{*}{ Углеводороды } & \multirow{4}{*}{$\begin{array}{c}\text { Темпе- } \\
\text { ратура } \\
\text { кипения, } \\
{ }^{\circ} \mathrm{C}\end{array}$} & \multicolumn{4}{|c|}{ Колонки } \\
\hline & & 1 & & 3 & 4 \\
\hline & & \multicolumn{2}{|c|}{$\begin{array}{c}\text { Апнезон Л, } \\
25 \%\end{array}$} & $\begin{array}{c}\text { Поли- } \\
\text { этилен- } \\
\text { гликоль- } \\
\text { адипинат, } \\
25 \%\end{array}$ & $\begin{array}{l}\text { Поли- } \\
\text { этилен- } \\
\text { гликоль- } \\
\text { фталат, } \\
25 \%\end{array}$ \\
\hline & & при $250^{\circ}$ & Іпрн $280^{\circ}$ & при $220^{\circ}$ & при $200^{3}$ \\
\hline Нафталин & 218 & 142 & - & 281 & 378 \\
\hline 2-Метилнафталин & 241 & 200 & - & 380 & 486 \\
\hline 1-Метилнафталин & 245 & 216 & - & 427 & 560 \\
\hline 2-Этилнафталин & 258 & 268 & - & 473 & 623 \\
\hline 1-Этилнафталин & 259 & 268 & - & 495 & 709 \\
\hline 2,7-Диметилнафталин & 262 & 289 & - & 517 & 663 \\
\hline 2,6-Диметилнафталин & 261 & 287 & - & 536 & 667 \\
\hline 1,7-Диметилнафталин & 263 & 305 & - & 546 & 725 \\
\hline 1,6-Диметилнафталин & 265,5 & 313 & - & 577 & 754 \\
\hline 2,3-Диметилнафталин & 268 & 334 & - & 652 & 881 \\
\hline 1,5-Диметилнафталин & 270 & 351 & - & 654 & 909 \\
\hline 1,4-Диметилнафталин & 268,5 & 339 & - & 670 & 856 \\
\hline 1,2-Диметилнафталии & 271 & 361 & - & 730 & 951 \\
\hline $\begin{array}{l}\text { 1-Пропилнафталин } \\
\text { Дифенил }\end{array}$ & $\begin{array}{l}274,5 \\
255\end{array}$ & $\overline{260}$ & 235 & 595 & 769 \\
\hline Дифенилметан & 264 & 271 & 241 & - & 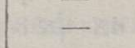 \\
\hline 1,1-Дифенилэтилен & 277 & 325 & 300 & $\overline{20}$ & - \\
\hline 1,2-Дифенилэтан & $\begin{array}{l}280,5 \\
240\end{array}$ & $\overline{200}$ & - & $\begin{array}{l}338 \\
180\end{array}$ & - \\
\hline Циклогексилбензол & & & & & \\
\hline
\end{tabular}

При разделении нафталиновых углеводородов на хроматограмме пики 2,3- и 1,5-диметилнафталйнов, 2,6- и 2,7-диметилнафталинов, 1,6и 1,7-диметилнафталинов совпадают. Отсюда видно, что идентификация диметилнафталинов невозможна на основе данных об относительных временах удерживания.

Учитывая вышеупомянутое, анализ ароматических углеводородов приводился по следуюлцей методике:

Широкие фракции смолы камерной печи хроматографировались на силикагеле. Выделенные ароматические углеводороды перегонялись в вакууме на узкие фракции. Количество и химический состав ароматических углеводородов узких фракций определялись газохроматографически. Полученные данные уточнялись полупрепаративным газохроматографическим методом и методом ультрафиолетового анализа.

Разработанная методика применялась при анализе фракции $180-$ $300^{\circ}$ смолы камерных печей СПК им. В. И. Ленина. Данные об отборе проб и их предварительной обработке приводились в ранее опубликованной работе [5]. Исследовались узкие фракции с пределами кипения $180-208^{\circ}$ (см. рис. 1, № 27-49 [5]) и широкие фракции с пределами кипения $210-312^{\circ}$ (см. табл. 1, № $3,4\left[{ }^{5}\right]$ ). Указанные широкие фракпии 
перегоняли * в вакуумной колонке ( 60 теоретических тарелок) на более узкие фракции. С полученных фракций снимались инфракрасные спектры. на спектрометре ИКС-14. Помимо этого полученные фракции анализировались газохроматографически, согласно вышеуказаннов̆ методике.

На основе данных о составе ароматических углеводородов, приведенных в табл. 3, можно сделать ряд заключений. Основными арома-

таблища 3

\section{Соедннення, идентнфицированные во фракция $180-300^{\circ}$ сланцевой смолы камерных печей}

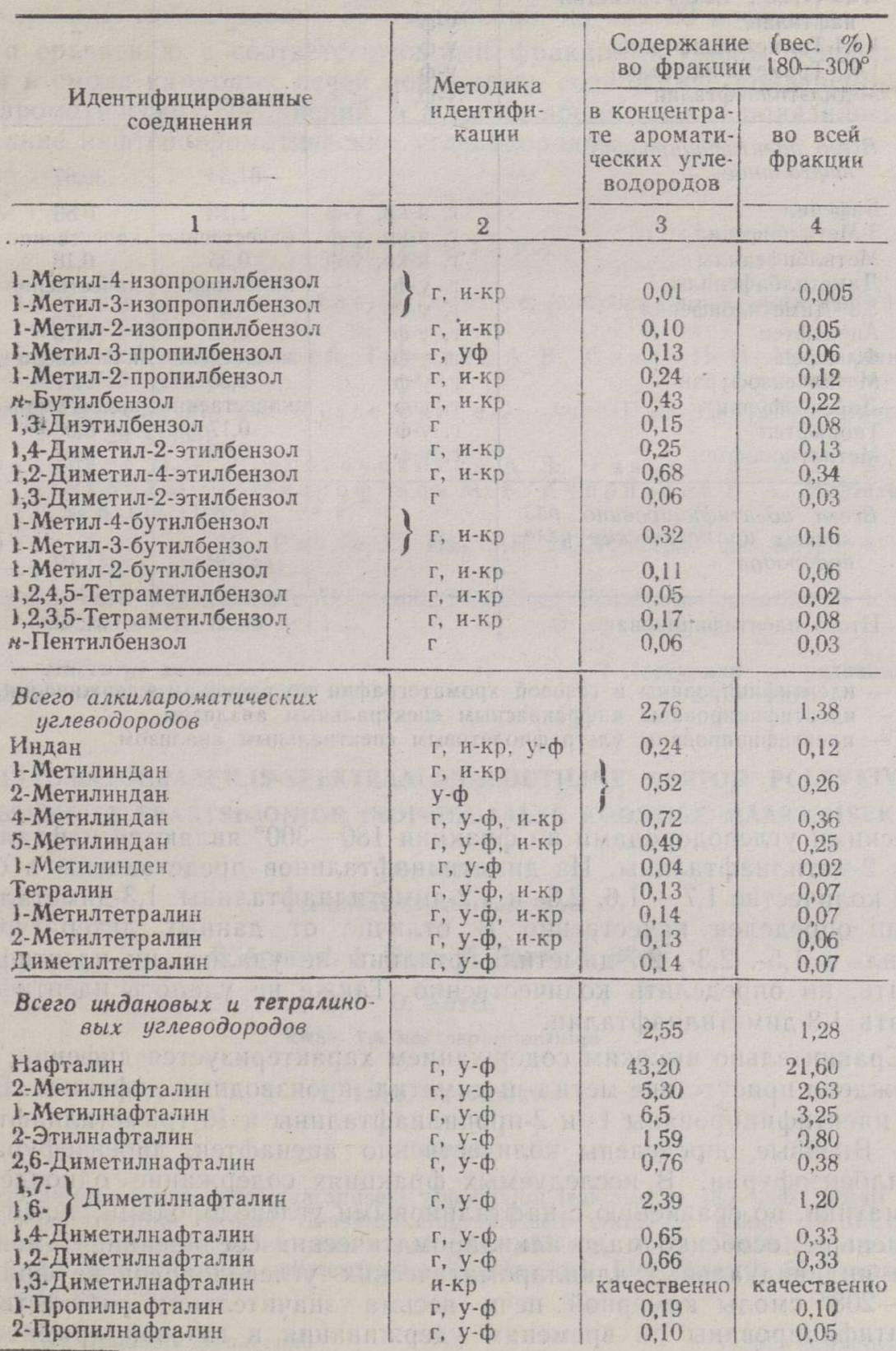

* Ректнфнкация проводилась с участием мл. науч. сотр. К. Арро. 
Продойение тап̄л. 3

\begin{tabular}{|c|c|c|c|}
\hline 1 & 2 & 3 & 4 \\
\hline $\begin{array}{l}\text { 1,3,6-Триметилнафталин } \\
\text { 1,2,3-Триметилнафталин } \\
\text { 1,2,6-(1,3,7-) Триметилнафталин } \\
\text { 1,2,7-Триметилнафталин } \\
\text { 1,3,5-Триметилнафталин } \\
\text { 1,2,5-Триметилнафталин } \\
\text { 1,2,8-Триметилнафталнн } \\
\text { 1,4,6-(1,4,5-; 1,2,5-) Триметил- }\end{array}$ & $\begin{array}{l}y-\phi \\
y-\phi \\
y-\phi \\
y-\phi \\
y-\phi \\
y-\phi \\
y-\phi\end{array}$ & $\begin{array}{c}\text { качественно } \\
, \\
" \\
" \\
" \\
,\end{array}$ & $\begin{array}{c}\text { качествениб } \\
, \\
, \\
, \\
, \\
, \\
,\end{array}$ \\
\hline $\begin{array}{l}\text { нафталин } \\
\text { 1,2,4-Триметилнафталин } \\
1,6,7-\text { Триметилнафталин } \\
\text { Метилэтилнафталин }\end{array}$ & $\begin{array}{l}y-\phi \\
y-\phi \\
y-\phi \\
y-\phi, r\end{array}$ & $\begin{array}{l}", \\
", \\
",\end{array}$ & $\begin{array}{l}, \\
, \\
,\end{array}$ \\
\hline $\begin{array}{l}\text { Всего идентифицировано } \\
\text { нафталинов }\end{array}$ & & 61,34 & 30,67 \\
\hline $\begin{array}{l}\text { Бифенил } \\
\text { 3-Метилбифенил } \\
\text { Метилбифенилы } \\
\text { Диметилбифенилы } \\
\text { 3,3'-Диметилбифенил } \\
\text { Аценафтен } \\
\text { Флюорен } \\
\text { Метилбензофуран } \\
\text { Дибензофуран } \\
\text { Тионафтен } \\
\text { Метилтионафтен }\end{array}$ & 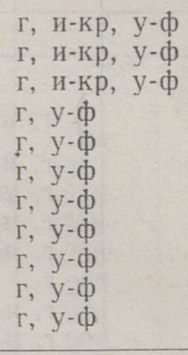 & $\begin{array}{c}1,13 \\
\text { качественно } \\
0,35 \\
\text { качественно } \\
0,30 \\
\text { качественно } \\
0,35 \\
\text { качественно } \\
0,17 \\
0,03\end{array}$ & $\begin{array}{c}0,56 \\
\text { качественжс } \\
0,18 \\
\text { качественно } \\
0,15 \\
\text { качественкі } \\
0,17 \\
\text { качественя } \\
0,08 \\
0,02\end{array}$ \\
\hline $\begin{array}{l}\text { Всего идентифицировано раз. } \\
\text { личных ароматических угле- } \\
\text { водородов }\end{array}$ & & 2,38 & 1,19 \\
\hline Итого идентифицировано & & 69,03 & 34,52 \\
\hline
\end{tabular}

r - идентифицированы в газовой хроматографии по временам удерживанғя. н-кр - идентифицированы инфракрасным спектральным анализом.

y-ф - идентифнцированы ультрафиолетовым спектральным анализом.

тическими углеводородами во фракции $180-300^{\circ}$ являются нафталин и 1 - и 2-метилнафталины. Из диметилнафталинов представлены в большом количестве $1,7+1,6,2,6$ - и 1,2-диметилнафталины. 1,3-диметилнафталин определен качественно. В отличие от данных литературы [6] 1-этил- и 1,5-, 2,3-, 2,7-диметилнафталины не удалось ни идентифицировать, ни определить количественно. Также не удалось идентифицировать 1,8-диметилнафталин.

Сравнительно высоким содержанием характеризуется дифенил; подтверждено присутствие метил- и диметил- производных дифенила. Впервые идентифицированы 1- и 2-пропилнафталины и 10 триметилнафталинов. Впервые определены количественно аценафтен, дибензофуран и метилбензофуран. В исследуемых фракциях содержание одноядерной ароматики, по сравнению с нафталиновыми углеводородами, значительно меньше, особенно мало алкилароматических соединений. Номе́нклатура индивидуальных алкилароматических углеводородов во фракции $180-208^{\circ}$ смолы камерной печи весьма значительна; количественно идентифицированы по временам удерживания в газовой хроматографии, а также на основе инфракрасного и ультрафиолетового спектраль- 
ного анализа, 16 алкилароматических углеводородов. С увеличением длины боковой цепи уменьшается содержание соответствующих соединений. например: нафталина содержится 43,2\%, 2-метилнафталина $5,30 \%, 2$-этилнафталина $-1,59 \%, 2$-пропилнафталина $-0,10 \% ;$-бутилбензола содержится $0,43 \%$ в то время как $н$-пентилбензола - 0,06\%. Относительно велико содержание производных ряда индана, тетралина и индена. Впервые в смоле эстонского горючего сланца определено наличие 4-метилиндана, 2-метилиндана, 1-метилиндена, 1-метилтетралина и 2-метилтетралина. Легко удалось газохроматографически выделить и спектрально идентифицировать тионафтен и метилтионафтен (рис. 1).

Bcero идентифицировано 59 соединений, из них 28 впервые.

По сравнению с соответствующими фракциями смолы туннельных печей в смоле камерных печей повысилось содержание конденсированных ароматических соединений, и в то же время сильно понизилось содержание нафтеноароматических углеводородов.

\title{
Л 1 T E P A T Y P A
}

1. Ta Chuang Lo Chang, Karr C 1 a rence, Analytica Chimica Acta, 24, 343-356 (1961).

2. Мусаев И. А., Гу Ци -вей, Топч и ев А. В., С анин П. И., Нефтехимия, 1, № 4,459 (1961).

3. van der Sticht M., van Rysselberge J., Journal of Gas Chromatography, No. 8,29 (1963)

4. Гоникберг М. Г., Дорогочинский А. 3., Гаврилова А. Е., Қома ненкова Р. А., Ми трофанов $M$. Г., Куприя нов В. А., Нефтехимия, 3, № 6, 916 (1963).

5. Эйзен О., А рро И., Р а уде Х., Изв. АН ЭССР, Серия физ.-матем. и техн. наук, № 4, 439 (1963).

6. A r ro I., Eesti NSV Teaduste Akadeemia Toimetised, Füüsika-matemaatika- ja tehnikateaduste seeria, 1964, nr. 1.

Институт хинии

Академии наук Эстонской ССР
Поступила в редакцию 2. III 1964

\section{GAASIKROMATOGRAAFILIS-SPEKTRAALANALÜUTILINE MEETOD PŌLEVKIVIŌLI KESKMISTE FRAKTSIOONIDE INDIVIDUAALSE KOOSTISE MÄÄRAMISEKS}

\author{
O. Eisen, \\ tehnikateaduste kandidaat
}

E. Arumeel, J. Eisen, H. Raude, I. Põder,

o. Kirret,

\section{ENSV TA korrespondentliige}

L. Lahe, M. Vänikver

Resümee

Aromaatsete süsivesinike määramiseks põlevkiviōli fraktsioonis $180-300^{\circ}$ töötati välja gaasikromatograafiline meetod. Gaasikromatograafiliselt eraldatud piikide identifitseerimine toimus ultravioletse ja infrapunase spektraalanalüüsiga. Määrati naftaliinaromaatsete. süsivesinike retentsiooniajad mitmesugustel vedelfaasidel. Identifitseeriti 59 aromaatset, hapniku- ja väävliühendit. 


\section{GASCHROMATOGRAPHISCHE METHODE FUR DIE BESTIMMUNG INDIVIDUELLER ZUSAMMENSETZUNG DER MITTLEREN FRAKTIONEN DES BRENNSCHIEFERTEERS}

o. Eisen, E. Arumeel, J. Eisen, H. Raude, I. Põder,

o. Kirret,

Korrespondierendes Mitglied der Akademie der Wissenschaften der Estnischen S.S.R.

L. Lahe, M. Vänikver

Zusammenfassung

Es wurde eine neue halbpräparativ-gaschromatographische Methode für die Bestimmung aromatischer Kohlenwasserstoffe ausgearbeitet. Die individuelle Zusammensetzung der Fraktionen wurde mit Hilfe von Ultraviolett- und Ultrarotspektroskopie bestimmt. In der Fraktion $180-300^{\circ}$ des Kammerofenteers wurden 59 individuelle Kohlenwasserstoffe, Schwefel- und Sauerstoffverbindungen quantitativ identifiziert.

\section{Institut für Chemie}

der Akademie der Wissenschaften der Estnischen S.S.R.

Eingegangen am 3. März 1964 